\title{
BRIEF
}

\section{Interprofessional Escape Room Improves Knowledge and Collaboration Among Nursing, Pharmacy and Physical Therapy Students}

\author{
Nicholas M. Fusco, PharmD, ${ }^{a}$ Kelly Foltz-Ramos, $\mathrm{PhD},{ }^{\mathrm{b}}$ Patricia J. Ohtake, $\mathrm{PhD}^{\mathrm{c}, \mathrm{d}}$ \\ ${ }^{a}$ University at Buffalo, School of Pharmacy and Pharmaceutical Sciences, Buffalo, New York \\ ${ }^{\mathrm{b}}$ University at Buffalo, School of Nursing, Buffalo, New York \\ ${ }^{\mathrm{c}}$ University at Buffalo, Office of the Vice President for Health Sciences, Buffalo, New York \\ ${ }^{\mathrm{d}}$ University at Buffalo, School of Public Health and Health Professions, Buffalo, New York
}

Corresponding Author: Nicholas M. Fusco, University at Buffalo, School of Pharmacy and Pharmaceutical Sciences, 216 Pharmacy Building, Buffalo, NY 14214. Tel: 716-645-1732. Email: nmfusco@buffalo.edu

Submitted July 28, 2021; accepted December 9, 2021; ePublished December 2021

Objective. The purpose of this study was to extend our understanding of escape room pedagogical design by investigating the impact of escape room puzzle content on changes in student immediate recall knowledge and demonstration of interprofessional skills during a subsequent interprofessional simulation.

Methods. Students from nursing, pharmacy and physical therapy programs were randomized to complete an escape room themed around acute management of sepsis (intervention group; $n=133$ ) or general acute care (control group; $n=129)$ prior to participating in a simulated patient discharge case conference. Students completed a knowledge assessment before the escape room, immediately after the escape room and immediately after the simulation. Additionally, students completed the Interprofessional Socialization and Valuing Scale (ISVS-21) before and after the experience along with a postprogram evaluation. Faculty rated student achievement of interprofessional learning objectives during the simulation using a standardized rubric.

Results. Students in the intervention group had higher scores on the knowledge test administered immediately after the escape room. ISVS-21 scores increased from pre to post for all participants. Interprofessional learning objectives, as evaluated by faculty, were met by $248(94.7 \%)$ students.

Conclusion. An interprofessional escape room with specific puzzle content improved students' immediate recall knowledge. In both groups, self-assessed interprofessional socialization improved and faculty assessed interprofessional learning objective attainment during subsequent simulation occurred. Escape rooms can be an innovative pedagogical tool that can positively impact immediate recall knowledge and interprofessional collaborative skills of health professions students.

Keywords: interprofessional education; educational game; escape room; students

\section{INTRODUCTION}

Health professions programs continue to develop novel approaches to interprofessional education (IPE) to ensure students graduate proficient in the Interprofessional Education Collaborative's core competencies for interprofessional collaborative practice. ${ }^{1,2}$ Learning experiences commonly used to develop these competencies include interprofessional small group case discussions, simulation-based learning experiences, and clinical collaborative practice experiences. ${ }^{3-5}$ However, interprofessional learning experiences with the goal of developing knowledge, in addition to communication and teamwork skills, continue to evolve.

In the past few years escape rooms have become popular in health professions education as an active learning strategy and are associated with improved knowledge and skill acquisition as compared to traditional educational strategies. ${ }^{6,7}$ Despite the growing popularity of escape rooms, many reports rely on student satisfaction and single group pre-post knowledge assessments. ${ }^{8-14}$ These data are limited by small sample size and lack of randomization. Furthermore, escape rooms are often stand-alone experiences that do not objectively evaluate student performance of interprofessional skills relevant to the clinical setting.

Given the lack of quality and pedagogical standards for health professions escape room design and assessment, the purpose of this study was to extend our understanding of escape room pedagogical design by investigating the impact of an escape room on students' immediate recall knowledge and demonstration of interprofessional collaboration during a subsequent, clinically relevant, simulated interprofessional patient discharge conference. We hypothesized that an escape room with specific puzzle content focused on a theme would improve students' immediate recall knowledge of that 
theme. Additionally, we hypothesized that irrespective of the puzzle content, students would demonstrate interprofessional collaborative skills during simulation.

\section{METHODS}

This activity, conducted in Fall 2019, was required for senior nursing, third-year pharmacy, and second-year physical therapy students. These cohorts were chosen as they were at similar stages of professional and clinical experience. Students earned credit for this activity in a required course. The activity included asynchronous online learning (1 hour) about sepsis management and post-operative hip precautions prior to the in-person activity, which consisted of the escape room and simulation. These topics were selected as students from each respective program had exposure to them. The online learning was curated by program faculty, and students accessed it independently approximately one week prior to the activity. The in-person activity took place in the School of Nursing Simulation Center at a mutually convenient time. Students were divided into teams of two pharmacy, two nursing, and one physical therapy student. Student teams were randomly assigned to either the intervention or control group and had 30 minutes to complete the escape room.

To assess the impact of the escape room puzzles (ie, the independent variable) on immediate recall knowledge, two separate escape rooms were designed. The intervention escape room included puzzles focused on the theme of sepsis management and post-operative precautions for patients following total hip arthroplasty. For example, a puzzle in the intervention escape room challenged students to interpret a contact precautions policy for a patient with a positive blood culture (Methicillin-resistant Staphylococcus aureus), which directly related to the theme of sepsis management. The control escape room included puzzles focused on general knowledge of acute care practice but did not relate to the theme of sepsis management and post-operative precautions.

After participating in the escape room, students completed the simulated patient discharge conference. They were tasked with creating and discussing an interprofessional discharge plan for an individual leaving an acute care facility following total hip arthroplasty complicated by sepsis. Students were given a patient chart and had 15 minutes to develop the plan and 15 minutes to educate the patient. A standardized actor, trained by faculty, played the role of the patient. Then, the standardized actor and a faculty member moderated a reflection-based debriefing using the Plus-Delta debriefing framework, consistent with best practices for interprofessional simulation. ${ }^{15,16}$

This study collected and analyzed three student self-reported data sources (a knowledge test, Interprofessional Socialization and Valuing Scale (ISVS-21), and a post-program evaluation) and one faculty reported data source (Modified McMaster-Ottawa Scale).

The knowledge test was an investigator developed, ten-item multiple choice test on sepsis management and postoperative hip precautions. The knowledge test was administered to all students on paper at three different time points: \#1 immediately prior to the escape room (baseline knowledge), \#2 immediately after the escape room, and \#3 immediately after the simulation.

The ISVS-21 self-assesses interprofessional socialization among students and health practitioners and their readiness to function in interprofessional teams. ${ }^{17}$ The reliability and validity of the instrument has been examined with a variety of health professionals with evidence supporting using the instrument pre and post IPE interventions. ${ }^{17}$ The ISVS21 consists of 21 -items using a seven-point Likert-type scale. Item scores are added together and divided by 21 to obtain an overall score.

The anonymous post-program evaluation consisted of six items. Four items asked students to rate their level of agreement that the activity met the learning objectives using a five-point Likert-type scale (1=strongly disagree, $2=$ disagree, $3=$ neutral, $4=$ agree and $5=$ strongly agree). Data for these four items were reported as the frequency of respondents that "Agree" or "Strongly Agree." The remaining two evaluation items were optional, open-ended questions that asked: what about this learning experience did you enjoy most and what would improve this learning experience. Responses were analyzed by two individuals using a thematic analysis, a method commonly used in qualitative research studies. ${ }^{18}$ The number and percent of responses coded for each theme was computed along with examples.

Faculty rating of individual students occurred during the simulated patient discharge conference using a four-item rubric. The rubric, adapted from the Modified McMaster-Ottawa scale which assesses individual student performance in interprofessional teams, ${ }^{19}$ consisted of four items assessed on a met/not met scale that mirrored the Interprofessional Education Collaborative's core competency domains of values and ethics, roles and responsibilities, communication and teamwork. ${ }^{1,2}$

All statistical tests were conducted using IBM Statistical Package for Social Science (SPSS) Version 26 software (SPSS Inc., Armonk, NY). For all statistical tests $p<.05$ were considered statistically significant. The University at Buffalo Institutional Review Board reviewed and approved this study. 


\section{RESULTS}

A total of 262 students participated in the activity, of which 129 were in the control group and 133 were in the intervention group. Characteristics were similar between groups (Table 1). Forty-two (33\%) students (8 groups) in the control group and $67(50 \%)$ students (14 groups) in the intervention group successfully escaped the room $(p=.003)$.

Prior to the escape room activity, students in both groups correctly answered a mean (SD) of 6.7 (1.8) questions correctly (Table 2). For participants in the intervention group a significant increase in mean score occurred between knowledge test \#1 and \#2 ( $p<.01)$ and \#1 and \#3 ( $p<.01)$, but not between \#2 and \#3 ( $p=1)$. For participants in the control group a significant increase in mean score occurred between knowledge test \#1 and \#3 ( $p<.01)$ and \#2 and \#3 ( $p=.003)$, but not between \#1 and \#2 ( $p=.09)$.

Prior to the activity, participants in both groups responded on average that they displayed the interprofessional beliefs, behaviors, and attitudes on the ISVS-21 "to a fairly great extent" [5.1 (0.9); Table 2). Following the activity, ISVS-21 scores increased similarly in both groups [control $(0.85(1.3)$; intervention $(0.96(1.2) ; p=.51)$ ] to a mean response of "to a great extent" [6.0 (0.8)].

A total of $248(94.7 \%)$ students met the interprofessional collaboration criteria as evaluated by faculty. There was no difference in the frequency of students that met the learning criteria between the control (95\%) and intervention (94\%) groups $(p=.38)$.

Overall, this learning activity was rated highly by participants $(n=156$; response rate $=60 \%)$. The frequency of students that "Agree" or "Strongly Agree" with each evaluation rating item were: the escape room was an effective way to develop interprofessional teamwork skills (90\%); the simulation (case conference) was an effective way to develop interprofessional collaboration skills (79\%); learning experiences like this are important to my professional development (85\%); and, learning experiences like this should be a required part of my interprofessional education (79\%). The qualitative analysis (Table 3 ) revealed three major themes for each question.

\section{DISCUSSION}

Participating in an interprofessional escape room with puzzles focused on a theme improved students' immediate recall knowledge of that theme that was sustained during simulation; whereas participation in an interprofessional escape room with general knowledge puzzles (ie, not related to a theme) resulted in no improvement in immediate recall knowledge of that theme. However, participation in simulation resulted in an increase in these (control group) students' knowledge to a point that was not different from the intervention group. Students demonstrated significant increases in interprofessional socialization and a high percentage of all students successfully met the interprofessional collaboration criteria as evaluated by faculty during simulation. Based on these findings, an escape room paired with a contextually relevant simulation may be an effective pedagogical tool to enhance students' immediate recall knowledge while positively impacting their socialization among other students and health practitioners and their readiness to function in interprofessional teams.

Pharmacy student participation in diabetes themed escape rooms increased immediate, but not delayed, postactivity knowledge suggesting that knowledge gained through the escape experience may not be retained. ${ }^{12}$ Our study did not include a delayed, post-activity assessment but our findings related to an increase in immediate recall knowledge are consistent with these data. Our data add to the existing literature by including students from multiple health professions programs, where data are lacking.

Qualitative feedback identified that students learned from each other during the experiences. A comment reflective of this was, "I think it was well planned. In terms of the three pre, mid and post quizzes we did, depending on what I heard my group member say during the escape room or even the simulation activity, some of my answers changed. So, I like how the activities were connected.” This comment supports the interprofessional experience, in that students were learning about, from, and with each other. ${ }^{20}$

All students, regardless of which escape room they were randomized to, experienced an increase in self-assessed interprofessional socialization. Previous studies examining interprofessional escape rooms on student attitudes found that students reported their team understood their roles and responsibilities, listened to each other, and that their individual opinions were valued. ${ }^{21,22}$ Our study is similar but enhance these existing data by adding the assessment of knowledge gained during the experience, while also analyzing two other important sources of data: 1) student self-assessed interprofessional socialization through a validated instrument ${ }^{17}$ and 2) faculty assessment of individual student performance within a team using the Modified McMaster-Ottawa Scale. ${ }^{19}$ These data complement the findings of knowledge gained by students by also revealing that self-assessed ability to engage in interprofessional teamwork improved and a high percentage of students achieved the interprofessional learning objectives as rated by observing faculty. 
Our data support the use of an escape room to increase students' knowledge related to a specific theme. Our study strengthens existing escape room pedagogy literature by: 1) using a large sample size, 2) including students from different health professions programs, 3) providing a comparison between participation in an intervention or control (sham) escape room, and 4) employing random group assignment. The observed group differences in mean knowledge test scores directly after the escape room likely reflect the knowledge gained through the themed escape room experience.

There were several limitations to this study. The program evaluation data revealed there were opportunities for improvement with the activities. Specifically, the physical therapy students commented that the physical therapist role was not as robust compared to the pharmacist and nurse roles. A high percentage of students achieved the interprofessional collaboration criteria evaluated by faculty. However, we did not objectively assess interprofessional competencies prior to the simulation experience. The experience included pharmacy, nursing, and physical therapy students only and could be enhanced by expanding the number of professions involved, including student prescribers. Lastly, the outcomes were evaluated immediately after the activity. The long-term impact of experiences such as this should be further studied.

\section{CONCLUSION}

An interprofessional escape room with specific puzzle content improved students' immediate recall knowledge. Self-assessed interprofessional socialization improved and faculty assessed interprofessional collaboration criteria attainment during simulation occurred irrespective of the puzzle content of the escape room. Escape rooms can be an innovative pedagogical tool that can positively impact immediate recall knowledge and interprofessional skills of students from multiple health professions programs.

\section{REFERENCES}

1. Interprofessional Education Collaborative Expert Panel. Core competencies for interprofessional collaborative practice: Report of an expert panel. https://ipec.memberclicks.net/assets/2011-Original.pdf. Accessed November $2,2021$.

2. Interprofessional Education Collaborative Expert Panel. Core competencies for interprofessional collaborative practice: 2016 update. https://ipec.memberclicks.net/assets/2016-Update.pdf. Accessed November 2, 2021.

3. Charrette AL, Sullivan KM, Kucharski-Howard J, Seed S, Lorenz L. Physical therapy and pharmacy interprofessional education in the context of a university pro bono physical therapy setting. $J$ Interprof Care. 2020;34(3):315-323. https://doi.org/10.1080/13561820.2019.1663160.

4. Fusco NM, Maerten-Rivera J, Doloresco F, Ohtake PJ. Improving Pharmacy Students' Attitudes Toward Collaborative Practice Through a Large-scale Interprofessional Forum Targeting Opioid Dependence. Am J Pharm Educ. 2019;83(6):Article 7034. https://doi.org/10.5688/ajpe7034.

5. Stockert B, Ohtake PJ. A National Survey on the Use of Immersive Simulation for Interprofessional Education in Physical Therapist Education Programs. Simul Healthc. Oct 2017;12(5):298-303. https://doi.org/10.1097/SIH.0000000000000231.

6. Brown N, Darby W, Coronel H. An Escape Room as a Simulation Teaching Strategy. Clin Simul Nurs. 2019;30:1-6. https://doi.org/10.1016/j.ecns.2019.02.002.

7. Gentry SV, Gauthier A, L'Estrade Ehrstrom B, et al. Serious Gaming and Gamification Education in Health Professions: Systematic Review. J Med Internet Res. 2019;21(3):e12994. https://doi.org/10.2196/12994.

8. Aubeux D, Blanchflower N, Bray E, et al. Educational gaming for dental students: Design and assessment of a pilot endodontic-themed escape game. Eur J Dent Educ. 2020;24(3):449-457. https://doi.org/10.1111/eje.12521.

9. Caldas LM, Eukel HN, Matulewicz AT, Fernandez EV, Donohoe KL. Applying educational gaming success to a nonsterile compounding escape room. Curr Pharm Teach Learn. 2019;11(10):1049-1054. https://doi.org/10.1016/j.cptl.2019.06.012.

10. Foltz-Ramos K, Fusco NM, Paige JB. Saving patient x: A quasi-experimental study of teamwork and performance in simulation following an interprofessional escape room. [published online head of print, 2021 Feb 15]. J Interprof Care. 2021:1-8. https://doi.org/10.1080/13561820.2021.1874316.

11. Guckian J, Eveson L, May H. The great escape? The rise of the escape room in medical education. Future Healthc J. 2020;7(2):112-115. https://doi.org/10.7861/fhj.2020-0032.

12. Kavanaugh R, George S, Lamberton N, Frenzel JE, Cernusca D, Eukel HN. Transferability of a diabetes escape room into an accelerated pharmacy program. Curr Pharm Teach Learn. 2020;12(6):709-715. https://doi.org/10.1016/j.cptl.2020.01.022.

13. Morrell BLM, Eukel HN. Escape the Generational Gap: A Cardiovascular Escape Room for Nursing Education. $J$ Nurs Educ. 2020;59(2):111-115. https://doi.org/10.3928/01484834-20200122-11. 
14. Podlog M, Husain A, Greenstein J, Sanghvi S. Escape the Trauma Room. AEM Educ Train. 2020;4(2):158-160. https://doi.org/10.1002/aet2.10410.

15. Cheng A, Eppich W, Epps C, Kolbe M, Meguerdichian M, Grant V. Embracing informed student self-assessment during debriefing: the art of plus-delta. Adv Simul (Lond). 2021;6(1):22. https://doi.org/10.1186/s41077-02100173-1.

16. INACSL Standards Committee. INACSL Standards of Best Practice: Simulation-Enhanced Interprofessional Education (Sim-IPE). Clin Sim Nurs. 2016;12:S34-S38. https://doi.org/10.1016/j.ecns.2016.09.011.

17. King G, Orchard C, Khalili H, Avery L. Refinement of the Interprofessional Socialization and Valuing Scale (ISVS-21) and Development of 9-Item Equivalent Versions. J Contin Educ Health Prof. 2016;36(3):171-177. https://doi.org/10.1097/CEH.0000000000000082.

18. Castleberry A, Nolen A. Thematic analysis of qualitative research data: Is it as easy as it sounds? Curr Pharm Teach Learn. 2018;10(6):807-815. https://doi.org/10.1016/j.cptl.2018.03.019.

19. Lie DA, Richter-Lagha R, Forest CP, Walsh A, Lohenry K. When less is more: validating a brief scale to rate interprofessional team competencies. Med Educ Online. 2017;22(1):1314751. https://doi.org/10.1080/10872981.2017.1314751.

20. World Health Organization. Framework for action on interprofessional educaiton \& collaborative practice. https://www.who.int/publications/i/item/framework-for-action-on-interprofessional-education-collaborativepractice. Accessed November 2, 2021.

21. Friedrich C, Teaford H, Taubenheim A, Boland P, Sick B. Escaping the professional silo: an escape room implemented in an interprofessional education curriculum. J Interprof Care. 2019;33(5):573-575. https://doi.org/10.1080/13561820.2018.1538941.

22. Friedrich C, Teaford H, Taubenheim A, Sick B. Interprofessional Health Care Escape Room for Advanced Students. J Nurs Educ. 2020;59(1):46-50. https://doi.org/10.3928/01484834-20191223-11. 
Table 1. Characteristics of Students that Participated in the Interprofessional Escape Room and Simulation Experience

\begin{tabular}{|c|c|c|c|}
\hline Variable & $\begin{array}{l}\text { Control }(n=129) \\
\text { n }(\%)\end{array}$ & $\begin{array}{l}\text { Intervention }(\mathrm{n}=\mathbf{1 3 3}) \\
\mathrm{n}(\%)\end{array}$ & $p$ value* \\
\hline \multicolumn{4}{|l|}{ Profession } \\
\hline Nursing & $55(43)$ & $54(41)$ & \\
\hline Pharmacy & $55(43)$ & $55(41)$ & \\
\hline Physical Therapy & $19(14)$ & $24(18)$ & .77 \\
\hline \multicolumn{4}{|l|}{ Age } \\
\hline 18 to 24 years & $97(75)$ & $98(74)$ & \\
\hline 25 to 34 years & $27(20)$ & 25 (19) & \\
\hline 35 to 44 years & $2(2)$ & $3(2)$ & \\
\hline 45 to 54 years & $1(1)$ & $0(0)$ & \\
\hline Prefer not to answer & $2(2)$ & $7(5)$ & .41 \\
\hline \multicolumn{4}{|l|}{ Gender } \\
\hline Male & $40(31)$ & $50(38)$ & \\
\hline Female & $87(67)$ & $76(57)$ & \\
\hline Prefer not to answer & $2(2)$ & $7(5)$ & .10 \\
\hline \multicolumn{4}{|l|}{ Related to or am a friend of a health professional or health professions } \\
\hline student in a profession other than my own. & $68(53)$ & $72(54)$ & .82 \\
\hline Previously graduated from a health professions program. & $9(7)$ & $5(4)$ & .25 \\
\hline $\begin{array}{l}\text { I have previous academic experience with health professionals } \\
\text { professions students in a profession other than my own. }\end{array}$ & $97(75)$ & $94(71)$ & .41 \\
\hline I have previous work or clinical experience with health profess & $80(60)$ & & \\
\hline $\begin{array}{l}\text { health professions students in a profession other than my own. } \\
\text { I have participated in an escape room. }\end{array}$ & $\begin{array}{l}89(69) \\
30(23)\end{array}$ & $\begin{array}{l}93(70) \\
40(30)\end{array}$ & $\begin{array}{l}.87 \\
.21\end{array}$ \\
\hline
\end{tabular}

*Chi-square was used to determine significance, defined as $p<.05$ 
Table 2. Comparison of Mean Scores on the Knowledge Tests and Interprofessional Socialization and Valuing Scale (ISVS-21) Between Control and Intervention Groups

\begin{tabular}{|c|c|c|c|}
\hline Variable & $\begin{array}{l}\text { Control }(n=129) \\
M(S D)\end{array}$ & $\begin{array}{l}\text { Intervention }(\mathrm{n}=133) \\
M(\mathrm{SD})\end{array}$ & $p$ value \\
\hline Knowledge Test \#1 & $6.7(1.6)$ & $6.8(1.9)$ & .78 \\
\hline Knowledge Test \#2 & $6.9(1.7)$ & $7.7(1.5)$ & $.01 *$ \\
\hline Knowledge Test \#3 & $7.3(1.7)$ & $7.7(1.6)$ & .06 \\
\hline Pre-ISVS-21 & $5.2(0.97)$ & $5.1(0.92)$ & .58 \\
\hline Post-ISVS-21 & $6.0(0.82)$ & $6.0(0.77)$ & .70 \\
\hline
\end{tabular}

${ }^{*}$ Two-way repeated measured analysis of variance was used to determine statistical significance, defined as $p<.05$ 
Table 3. Qualitative Themes Derived from a Program Evaluation Completed by Students that Participated in the Interprofessional Escape Room and Simulation Activity

\begin{tabular}{|c|c|c|c|}
\hline Question & Theme & $\%^{*}$ & Sample comments \\
\hline \multirow{4}{*}{$\begin{array}{l}\text { What about this } \\
\text { learning experience } \\
\text { did you enjoy most? } \\
(\mathrm{n}=140)\end{array}$} & & & $\begin{array}{l}\text { "The escape room was a lot of fun and was a nice way to break down any potential } \\
\text { barriers between us to force us to work together." }\end{array}$ \\
\hline & $\begin{array}{l}\text { Innovative approach to } \\
\text { interprofessional education }\end{array}$ & 38 & $\begin{array}{l}\text { "The escape room was great, and I actually learned stuff that I used on the } \\
\text { simulation. The interactive fun part helped me retain the knowledge." }\end{array}$ \\
\hline & $\begin{array}{l}\text { Opportunity to collaborate } \\
\text { with students of other } \\
\text { health professions }\end{array}$ & 28 & $\begin{array}{l}\text { "I really enjoyed working with students from other healthcare fields to solve the } \\
\text { problems presented to us." } \\
\text { "The input that the other teammates brought to the table; there were a lot of things I } \\
\text { would not have noticed if not for my teammates." }\end{array}$ \\
\hline & $\begin{array}{l}\text { Learning roles and } \\
\text { responsibilities of team } \\
\text { members }\end{array}$ & 12 & $\begin{array}{l}\text { "I liked the opportunity to see what other professions do and how I can rely on } \\
\text { them for certain aspects of care in my profession." } \\
\text { "Learning about other professions and seeing how they treat their patients. Seeing } \\
\text { the different ways each discipline approached the same problem was interesting." }\end{array}$ \\
\hline \multirow{4}{*}{$\begin{array}{l}\text { What would improve } \\
\text { this learning } \\
\text { experience? }(n=106)\end{array}$} & $\begin{array}{l}\text { More information prior to } \\
\text { simulation activity }\end{array}$ & 25 & $\begin{array}{l}\text { "The second part of the activity - the simulation - would have been more efficient } \\
\text { if we could have prepared for it ahead of time." }\end{array}$ \\
\hline & $\begin{array}{l}\text { More time to complete } \\
\text { escape room }\end{array}$ & 22 & $\begin{array}{l}\text { "I wish we had more time in the escape room." } \\
\text { "I think the escape room should be more time because it felt rushed." }\end{array}$ \\
\hline & & & $\begin{array}{l}\text { "In my opinion, the simulation was mainly geared toward pharmacy and nursing } \\
\text { with little to do with physical therapy, so having more of an emphasis on that } \\
\text { would be beneficial." }\end{array}$ \\
\hline & $\begin{array}{l}\text { Expand role of physical } \\
\text { therapist in team }\end{array}$ & 20 & $\begin{array}{l}\text { "Make the physical therapist role larger. Most of the tasks were directed toward } \\
\text { pharmacy and nursing students." }\end{array}$ \\
\hline
\end{tabular}

*Percentages calculated out of the total number of students that responded to particular item 